Article

\title{
Modelling of Evaporator in Waste Heat Recovery System using Finite Volume Method and Fuzzy Technique
}

\author{
Jahedul Islam Chowdhury, Bao Kha Nguyen * and David Thornhill \\ Received: 29 October 2015; Accepted: 7 December 2015; Published: 12 December 2015 \\ Academic Editor: Ling Bing Kong \\ School of Mechanical and Aerospace Engineering, Queen's University Belfast, Belfast BT9 5AH, UK; \\ jchowdhury01@qub.ac.uk (J.I.C.); D.Thornhill@qub.ac.uk (D.T.) \\ * Correspondence: b.nguyen@qub.ac.uk; Tel.: +44-28-9097-4769; Fax: +44-28-9097-4148
}

\begin{abstract}
The evaporator is an important component in the Organic Rankine Cycle (ORC)-based Waste Heat Recovery (WHR) system since the effective heat transfer of this device reflects on the efficiency of the system. When the WHR system operates under supercritical conditions, the heat transfer mechanism in the evaporator is unpredictable due to the change of thermo-physical properties of the fluid with temperature. Although the conventional finite volume model can successfully capture those changes in the evaporator of the WHR process, the computation time for this method is high. To reduce the computation time, this paper develops a new fuzzy based evaporator model and compares its performance with the finite volume method. The results show that the fuzzy technique can be applied to predict the output of the supercritical evaporator in the waste heat recovery system and can significantly reduce the required computation time. The proposed model, therefore, has the potential to be used in real time control applications.
\end{abstract}

Keywords: evaporator modelling; finite volume; fuzzy; Organic Rankine Cycle (ORC); supercritical condition; waste heat recovery

\section{Introduction}

Most of the energy produced by internal combustion engines is expelled to the environment via the exhaust and coolant systems. The expelled energy makes the engine running cost high and is one of the major causes of global warming and environmental pollution. In order to reduce fuel consumption, waste heat recovery (WHR) has been a growth research area in recent years. The WHR system is used to collect the heat from the exhaust or coolant and convert it into either mechanical or electrical power, which increases the thermal efficiency of the engine [1]. Among different methods to recover the waste heat, the Organic Rankine Cycle (ORC) is the most promising and widely used technology because of simplicity and availability of its components [2,3]. The working fluid used in the ORC is an organic substance (i.e., hydrocarbons or refrigerants), which has the properties of high molecular weight and low boiling point that are suitable for low grade heat recovery applications.

The ORC WHR system consists of four major components: pump, evaporator, expander and condenser, as shown in Figure 1. Liquid refrigerant is pumped to the evaporator where it is heated and vaporized by the heat sources. This vaporized fluid is then expanded and produces mechanical energy output through the shaft of the expander. A generator is normally coupled with the expander shaft to convert mechanical energy into electrical power. Exhaust products from the expander pass through the condenser where secondary cooling fluid removes extra heat and converts the exhaust back to a liquid. 


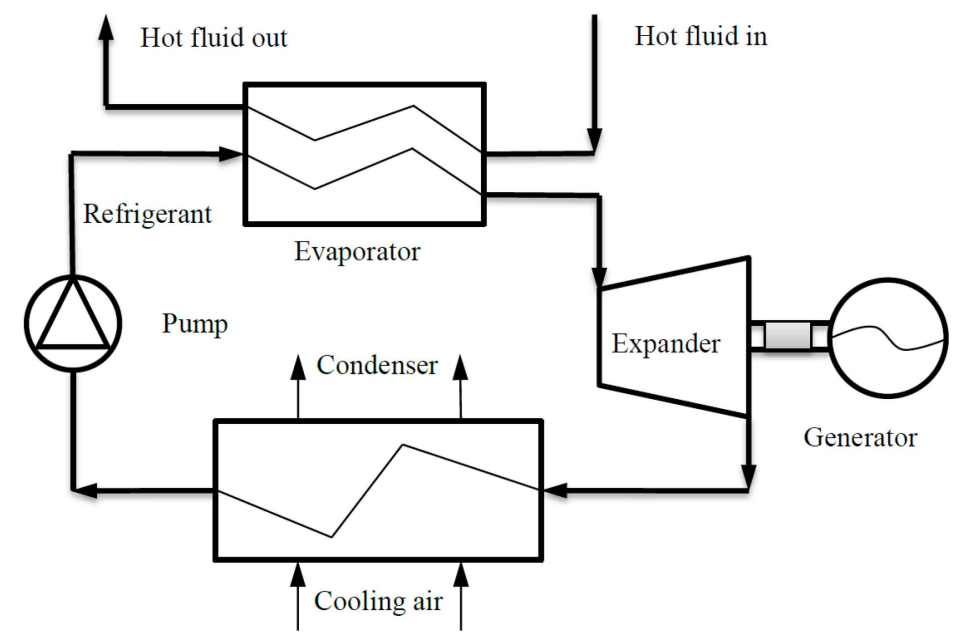

Figure 1. Components of a typical Organic Rankine Cycle (ORC) WHR system.

Depending on the working pressure, the evaporator of the ORC WHR can operate under two conditions: Subcritical and supercritical. The operating pressure of the subcritical evaporator is below the critical pressure of the working fluid, whereas in supercritical conditions, it is above the critical pressure. The operating pressure of the evaporator has an effective influence on the work output and efficiency of the ORC based WHR system. The efficiency of an ORC in subcritical conditions is low as the cycle is run at a lower pressure ratio and the exergy destruction and loss is found to be high [4]. The initial investigation carried out by Glover et al. [1], Schuster et al. [4], Shu et al. [5] and Gao et al. [6] show that the heat addition to the working fluid at supercritical pressure can lead to the highest efficiency of the cycle. This is due to the higher net power output, lower exergy losses and destruction, and better thermal match between heat source and working fluid. However, the benefits of the supercritical ORC are dependent on the types of heat, working fluids, operating conditions and cycle configuration used. Lecompt et al. [7] showed that the second law efficiency of a supercritical cycle for low temperature waste heat recovery is $10.8 \%$ more than a subcritical cycle. Chen et al. [8] showed that a supercritical ORC with a zeotropic mixture as the working fluid can improve the thermal efficiency by $10 \%-30 \%$ more than the subcritical ORC.

Modelling of the evaporator in the ORC WHR system has been addressed in several reports [2,9-17]. Three common modelling techniques are normally used for the evaporator: single segment lump method, three zone method and distributed or finite volume (FV) method [11]. The single segment technique treats the evaporator as a single-phase (i.e., liquid) heat exchanger. This method is only appropriate when the specific heat capacity of the fluid does not change with temperature. A zone modelling technique can be used where the evaporator has three distinct phases: liquid, liquid-vapour and vapour zone [15]. This method cannot be used where a distinct fluid phase is absent. The finite volume technique splits the evaporator into small segments and heat transfer equations are solved iteratively $[2,18,19]$. In the FV method, the thermo-physical properties are assumed to be constants at each segment of the evaporator since the temperature variation of the segment is low and is normally neglected.

Although the calculations of the evaporator model using single segment or zone-wise methods are clear, the influence of the working pressure on the WHR system are not considered in these methods. When the evaporator operates under supercritical conditions, the thermo-physical properties of the working fluid change with temperature (Figure 2) and there is no distinct fluids phase at these conditions [18]. For these reasons, a single segment lump method with constant fluid properties or a zone-wise technique cannot be used to calculate the heat transfer under supercritical conditions. In order to capture the thermo-physical property changes of the fluid, the finite volume method [18] has been developed for modelling of the evaporator in supercritical conditions. 


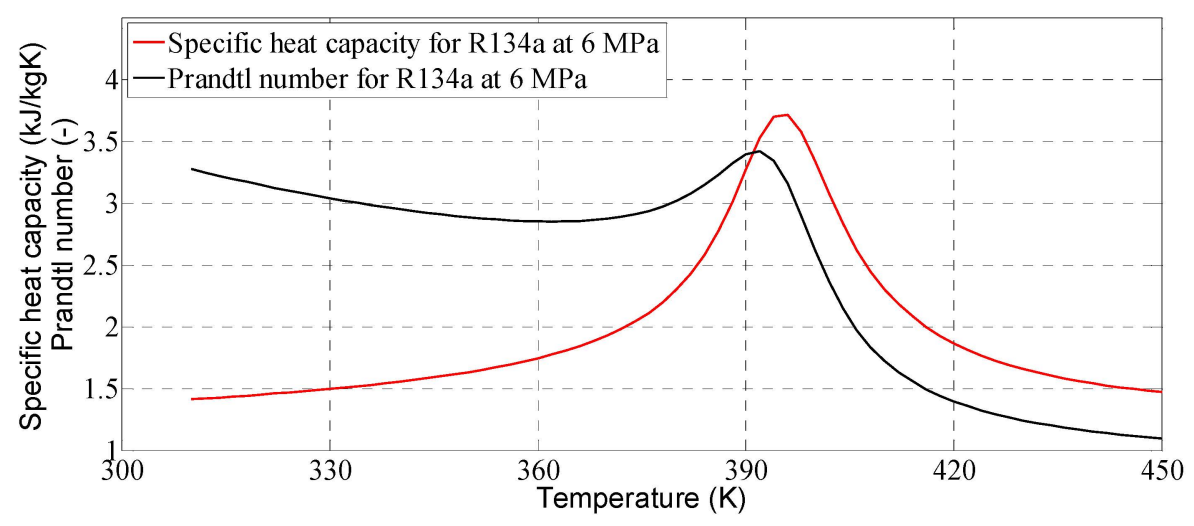

Figure 2. Variation of specific heat capacity and Prandtl number with temperature.

Despite high accuracy and robustness [18], the finite volume modelling technique is a highly time consuming method since it consists of many iterative loops [11,19], therefore, it has a limitation in real time control applications. In order to reduce the computation time of the evaporator model, a new evaporator model using the fuzzy inference technique is introduced and described in this paper.

Fuzzy logic [20] has been used to identify nonlinear systems, which avoids the need to have a complex model and saves computation cost and time during simulation and real time control applications [21]. A fuzzy model is generally built with experimental input-output data or an original mathematical model of the system [22]. Both the antecedent (input) and the consequent (output) of the fuzzy model are represented by fuzzy sets [23]. A defuzzification unit converts the fuzzy output into a single value (crisp value) by combining and weighting of the fuzzy sets. In order to assess fuzzy model performance, the crisp outputs can be compared with the actual values of the system [23].

This paper investigates two different modelling techniques for the evaporator operating at the supercritical condition. The first model uses the finite volume method; while the second model uses the fuzzy inference technique. Details of the fuzzy based evaporator model and its performance compared with the conventional finite volume method is presented in this paper.

The rest of the paper is presented as follows: Section 2 introduces different types of evaporator used in WHR systems. A detailed description and the working principles of the finite volume along with its simulation results are presented in Section 3. The design of the fuzzy based evaporator model and a comprehensive analysis of its outputs and the accuracy in comparison with the finite volume model are presented in Section 4. Concluding remarks are provided in Section 5.

\section{Evaporator in Waste Heat Recovery (WHR) System}

The evaporator is considered as the critical part of the ORC waste heat recovery system since heat transfer at supercritical pressure takes place within this component. Several types of heat exchangers are used as the evaporator in WHR systems, such as finned tube, shell and tube, plate, etc. The selection of heat exchanger mainly depends on the operating conditions, types and phase of fluids, and flow rate and heat transfer requirements of the system [24]. An externally finned tube type heat exchanger is mostly used for the heat recovery from a gas with the liquid on the inside of the tube $[16,24,25]$. A shell and tube and plate-type heat exchangers are commonly used for liquid to liquid heat recovery applications $[2,24,26]$.

Among conventional heat exchangers available in the market, a plate heat exchanger (Figure 3) is highly compact and has the advantage of a large heat transfer area that can recover the maximum amount of heat from the heat sources [5]. This type of heat exchanger is therefore used for the simulation in this paper. The geometrical parameters of the selected evaporator are shown in Table 1. 


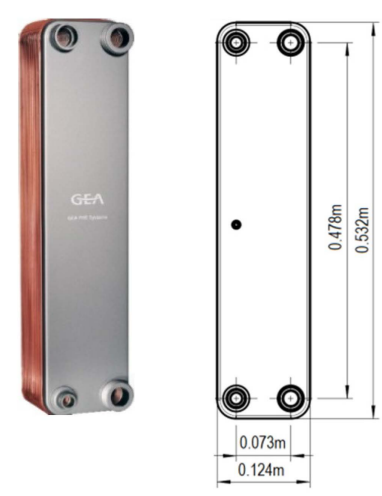

Figure 3. Plate heat exchanger [27].

Table 1. Geometrical parameters of the evaporator.

\begin{tabular}{ccc}
\hline Parameter & Quantity & Value \\
\hline $\mathrm{A}$ & Heat transfer area of the evaporator & $5.78 \mathrm{~m}^{2}$ \\
$\mathrm{~L}$ & Length of each plate of the evaporator & $0.478 \mathrm{~m}$ \\
$\mathrm{~W}$ & Width of each plate of the evaporator & $0.124 \mathrm{~m}$ \\
$\mathrm{~N}_{\mathrm{p}}$ & Number of plates & 100 \\
$\mathrm{~K}$ & Thermal conductivity & $15 \mathrm{~W} / \mathrm{m} \mathrm{K}$ \\
\hline
\end{tabular}

\section{Modelling of Evaporator Using the Finite Volume Method}

In the finite volume (FV) technique, the evaporator is divided into small segments along the flow direction as shown in Figure 4, and the heat transfer equations for each segment are solved iteratively [19]. The FV evaporator model is built with the following fundamental assumptions:

- $\quad$ There is no pressure loss in either the hot or cold side of the heat exchanger.

- Heat transfer from or to the surrounding environment is negligible.

- Heat exchanger fouling is not included in the model.

- Heat from the hot fluid is completely transferred to the working fluid.

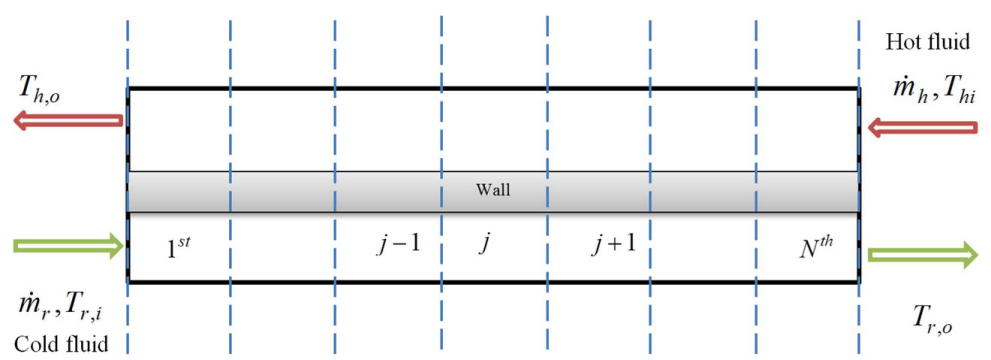

(a)

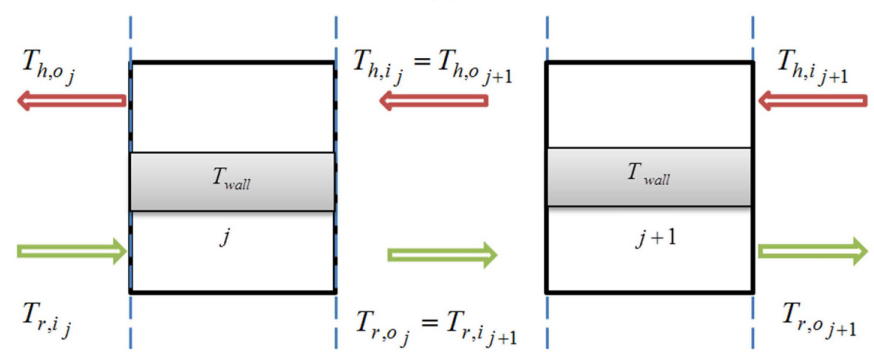

(b)

Figure 4. (a) Finite volume evaporator model; (b) Relationship between input and output variables. 
The input parameters of the evaporator model are: mass flow rate and temperature of the refrigerant $\left(\dot{m}_{r}, T_{r}\right)$ and hot fluid $\left(\dot{m}_{h}, T_{h}\right)$ and the outputs parameters are: evaporator power $\left(Q_{e v}\right)$ and outlet temperature $\left(T_{e v}\right.$ or $T_{r, o}$ and $\left.T_{h, o}\right)$, as shown in Figure 5 . Among the input parameters, the refrigerant inlet temperature is assumed to be constant and equal to a temperature of $303 \mathrm{~K}$. However, using FV method, the outlet temperatures of the hot and cold fluid are not known, but are initially estimated and an iteration process is carried out for each segment. The iteration starts from the $1^{\text {st }}$ segment and finishes at the $N^{\text {th }}$ segment as shown in Figure 4 . For each segment or cell $j$ in Figure 4, the heat transfer from the hot fluid to the wall and the wall to the refrigerant can be calculated in (1) and (2) as follows:

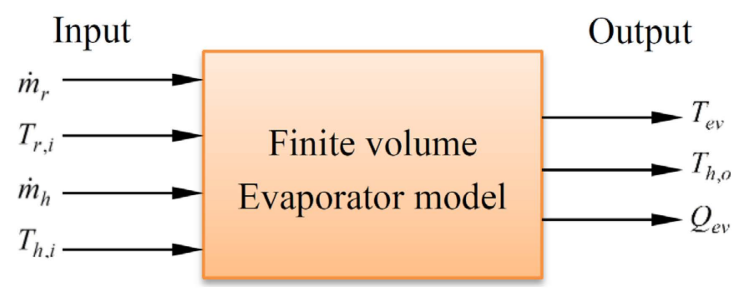

Figure 5. Input-output of finite volume evaporator model.

$$
\begin{gathered}
Q_{h_{j}}=h_{h_{j}} A_{h_{j}}\left(T_{h}-T_{\text {wall }}\right)_{j} \\
Q_{r_{j}}=h_{r_{j}} A_{r_{j}}\left(T_{\text {wall }}-T_{r}\right)_{j}
\end{gathered}
$$

where $Q_{h_{j}}$ and $Q_{r_{j}}$ refers to the amount of heat $(\mathrm{kW})$ transferred from the hot fluid to the wall and the wall to the refrigerant respectively. $h_{h_{j}}$ and $h_{r_{j}}$ are the convective heat transfer coefficients $\left(\mathrm{kW} / \mathrm{m}^{2} \mathrm{~K}\right)$ of the hot fluid and refrigerant with the wall. $A_{h_{j}}$ and $A_{r_{j}}$ are the heat transfer surface areas, $T_{h}$ and $T_{r}$ are the hot fluid and refrigerant's average temperature, within each finite volume, respectively. $T_{\text {wall }}$ is the wall temperature, which can be obtained from the average of the hot fluid and refrigerant temperature of the cell. These parameters are calculated as follows:

$$
\begin{gathered}
T_{h}=\frac{T_{h, i}+T_{h, o}}{2} \\
T_{r}=\frac{T_{r, i}+T_{r, o}}{2} \\
T_{\text {wall }}=\frac{T_{h}+T_{r}}{2}
\end{gathered}
$$

where $T_{h, i}, T_{h, o}$ are the hot fluid temperature and $T_{r, i}, T_{r, o}$ are the refrigerant temperature at the inlet and outlet of each segment.

Heat transfer due to the change in temperature of the hot fluid is calculated in Equation (6); whereas heat transfer due to the change in enthalpy of the refrigerant is calculated in Equation (7) as follows:

$$
\begin{gathered}
Q_{h j}=\dot{m}_{h j} C_{p, h j}\left(T_{h, i}-T_{h, o}\right)_{j} \\
Q_{r_{j}}=\dot{m}_{r_{j}}\left(H_{r, o}-H_{r, i}\right)_{j}
\end{gathered}
$$

where $\dot{m}_{h j}(\mathrm{~kg} / \mathrm{s})$ and $\dot{m}_{r_{j}}(\mathrm{~kg} / \mathrm{s})$ are the mass flow rates of the hot fluid and refrigerant respectively, $C_{p, h j}(\mathrm{~kJ} / \mathrm{kg} \mathrm{K})$ is the specific heat capacity of the hot fluid, and $H_{r j}(\mathrm{~kJ} / \mathrm{kg})$ is the enthalpy of the refrigerant.

The thermo-physical properties of the working fluid around the critical temperature are strongly variable at critical pressure [18]. For this reason, the Jackson correlation for supercritical fluids [28,29] is used to calculate the Nusselt number $N u$ for the refrigerant in Equation (8). This neutralizes the 
variation effects around the pseudo-critical point. For the hot fluid, it is calculated with Equation (11) using the Dittus Boelter correlation as suggested by Sharabi et al. [30].

$$
\begin{gathered}
N u_{r}=0.0183 \operatorname{Re}_{b}{ }^{0.82} \operatorname{Pr}^{0.5}\left(\frac{\rho_{\text {wall }}}{\rho_{b}}\right)^{0.3}\left(\frac{\bar{c}_{p}}{c_{p b}}\right)^{n} \\
\bar{c}_{p}=\frac{H_{w}-H_{b}}{T_{w}-T_{b}} \\
n=0.4 \text { for } T_{b}<T_{\text {wall }}<T_{p c} \text { and } 1.2 T_{p c}<T_{b}<T_{\text {wall }} \\
n=0.4+0.2\left(\frac{T_{\text {wall }}}{T_{p c}}-1\right) \text { for } T_{b}<T_{p c}<T_{\text {wall }} \\
n=0.4+0.2\left(\frac{T_{\text {wall }}}{T_{p c}}-1\right)\left(1-5\left(\frac{T_{b}}{T_{p c}}-1\right)\right) \text { for } T_{p c}<T_{b}<1.2 T_{p c} \text { and } T_{b}<T_{\text {wall }} \\
N u 0.023 \operatorname{Re}^{0.8} \operatorname{Pr}^{0.3}
\end{gathered}
$$

where $T_{b}$ is the bulk temperature of the refrigerant, $T_{p c}$ is the pseudo-critical temperature of the refrigerant; $\bar{c}_{p}$ is the average specific heat capacity of the medium; $\rho_{\text {wall }}$ is the density of the working fluid at wall temperature and $\rho_{b}$ is the density of the working fluid at bulk temperature; $H_{\text {wall }}$ and $H_{b}$ are the enthalpy of the working fluid at wall and bulk temperature, respectively. In this case, the bulk temperature is the same as the average refrigerant temperature of the cell.

The convective heat transfer coefficients of the fluids are calculated in Equation (12) and the Reynolds number Re is calculated in Equation (13):

$$
\begin{aligned}
& N u=\frac{h D_{h}}{K} \\
& \operatorname{Re}=\frac{\rho V D_{h}}{\mu}
\end{aligned}
$$

where $D_{h}$ is the hydraulic diameter of the plate heat exchanger, $\rho$ is the density $\left(\mathrm{kg} / \mathrm{m}^{3}\right)$ of the fluid, $\mu$ is the viscosity (Pa.s) and $V$ is the velocity of the fluids (m/s).

Figures 6 and 7 show the finite volume iteration process to calculate the outputs of the evaporator model. The steps of the iteration process are described as follows:

Step 1: All inputs of the model are defined at the beginning of the iteration process. The first segment is then initialized by assigning an initial inlet refrigerant temperature and assuming an initial hot fluid outlet temperature as shown in Figure 6.

Step 2: Set the initial values for the inlet, outlet and wall temperatures of the segment $j=1$ as shown in Figure 7.

Step 3: When all inlet and outlet temperatures of the first segment are known, the wall temperature of the evaporator is iteratively evaluated until the heat transfer rates in Equations (1) and (2) are equal with a selected maximum deviation of $\varepsilon_{1}=0.1$.

Step 4: The heat transfer rate of the fluids at Step 3 is used to calculate the output variables of each segment by using the energy balance condition of the fluids. The iteration at this step is repeated until the deviations are within the allowable limits of the convergence values as shown in Table 2. The values are a compromise chosen to reduce the computation time while achieving reasonable model accuracy.

Step 5: At this stage, the outlet variables of the first segment are all known. The iteration process continues along the refrigerant flow direction, the output variables of the first segment are used 
as the input of the second segment as shown in the Figure $4 \mathrm{~b}$ and the steps $2-4$ repeated until the deviations are satisfied. This process is repeated until the $N^{\text {th }}$ segment as shown in Figure 6.

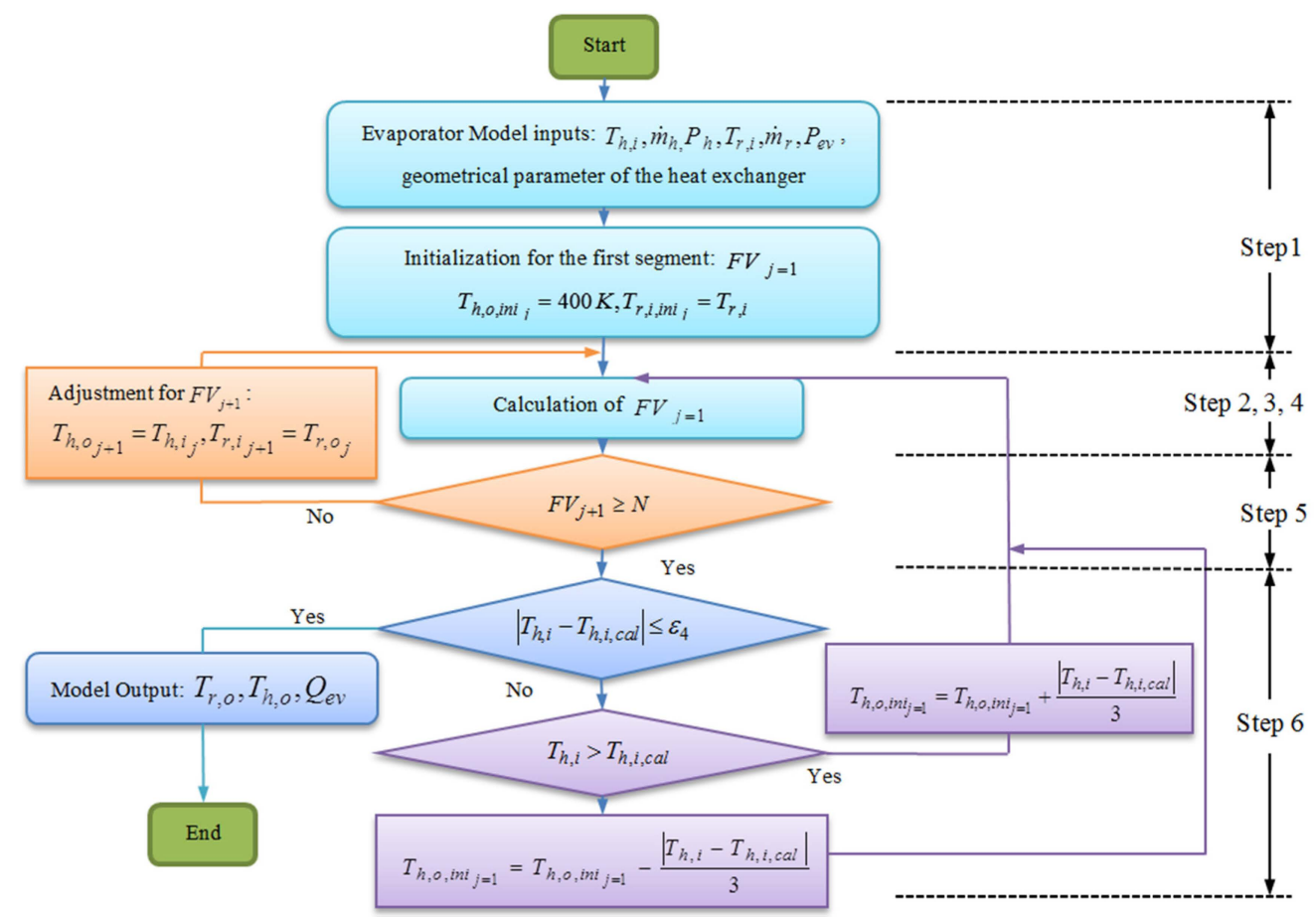

Figure 6. Finite volume calculations for all segments of the evaporator.

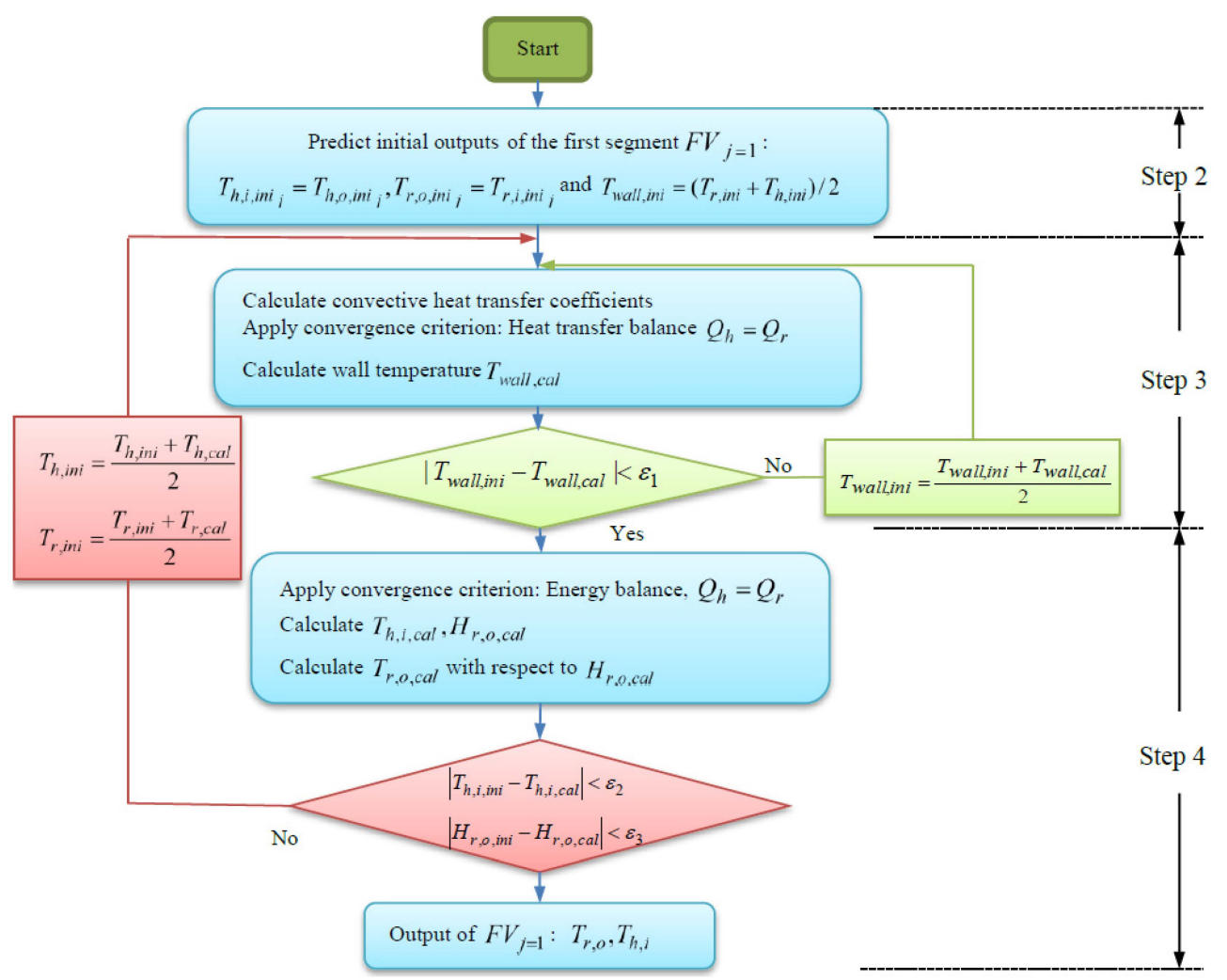

Figure 7. Finite volume calculations for the first segment $F V$. 
Table 2. Convergence value for iteration loops.

\begin{tabular}{cc}
\hline Convergence Name & Convergence Value \\
\hline$\varepsilon_{1}$ & 0.1 \\
$\varepsilon_{2}$ & 0.1 \\
$\varepsilon_{3}$ & 0.1 \\
$\varepsilon_{4}$ & 0.2 \\
\hline
\end{tabular}

Step 6: At the end of the $N^{\text {th }}$ segment, the calculated hot fluid temperature at the inlet of the evaporator $T_{h, i, c a l}$ is obtained. This calculated temperature is then compared with the real hot fluid data. If the error between the calculated and real temperature is less than the deviation shown in Table 2, the iteration process stops. Otherwise, the iteration process is repeated at steps 1-6.

\section{Simulation Results of Finite Volume Evaporator Model}

The working fluid used in the simulation of the evaporator is R134a refrigerant and hot water is used as the heat source. Several mass flow rate profiles of the R134a refrigerant were used to evaluate the evaporator model. Figure 8 shows two different random mass flow rate profiles including a random ramp profile in the simulation. The range of these profiles was from $28.6 \mathrm{gm} / \mathrm{s}$ to $250 \mathrm{gm} / \mathrm{s}$. These values were chosen based on the minimum and maximum delivery capacity of the pump normally used in the WHR process. The generic heat source in terms of variable mass flow rate and temperature (Figure 9) defined by Quoilin et al. [2] was used in this paper. This heat source was considered to be the hot water under pressure and could typically represent the total heat that is collected from an internal combustion engine's exhaust and coolant, via a secondery heat transfer fluid loop.

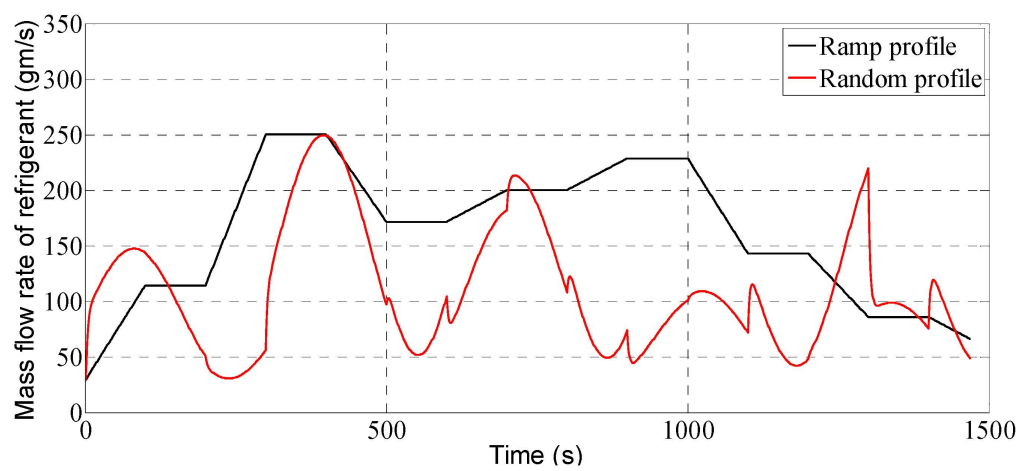

Figure 8. The mass flow rate of refrigerant profiles.

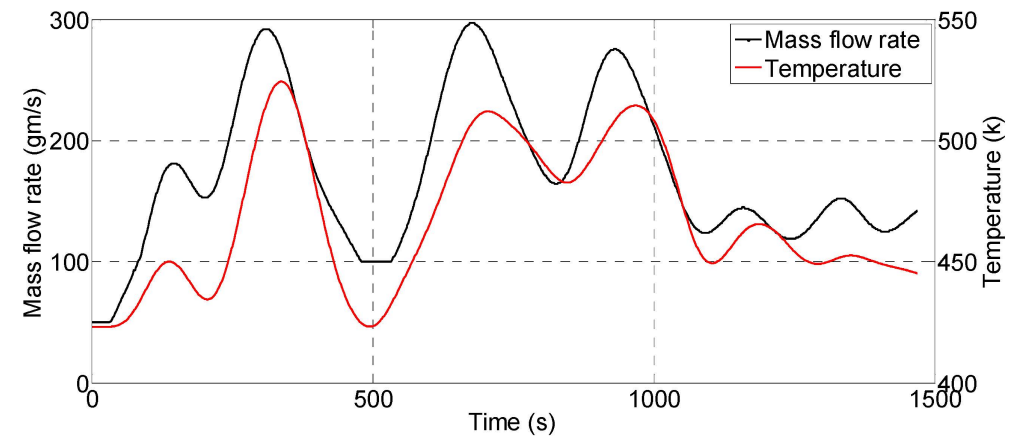

Figure 9. Heat source mass flow rate and temperature. 
The performances of the evaporator model were tested at a supercritical pressure of $6 \mathrm{MPa}$. This value is far away from the critical pressure of the R134a refrigerant which is $4.06 \mathrm{MPa}$. As mentioned in Karellas et al. [18], when the pressure of the evaporator rises, the error of the finite volume calculation is reduced and the procedure converges with fewer segments. The numbers of segments for the evaporator were set to 20 in the simulation, as it is a good compromise between iteration time and the accuracy of the model. The pseudo-critical temperature of R134a was set to $395 \mathrm{~K}$ which is constant at the reference pressure of $6 \mathrm{MPa}$. The thermo-physical properties of the refrigerant and hot water used in the simulation were obtained from the U.S. National Institute of Standards and Technology (NIST) database called REFPROP [31].

The evaporator power and evaporator outlet temperature from the FV model are shown in Figures 10 and 11 respectively. Figure 10 shows the variation of heat power absorbed by the evaporator with respect to the selected mass flow rate profiles in Figure 8. It can be seen from the figure that a maximum heat of $63.3 \mathrm{~kW}$ for the ramp profile and $55.2 \mathrm{~kW}$ for the random profile can be recovered from the given heat sources. The variation of evaporator outlet temperature in Figure 11 shows that a maximum temperature of $433 \mathrm{~K}$ for the ramp profile and $469 \mathrm{~K}$ for the random profile are achieved at the outlet of the evaporator.

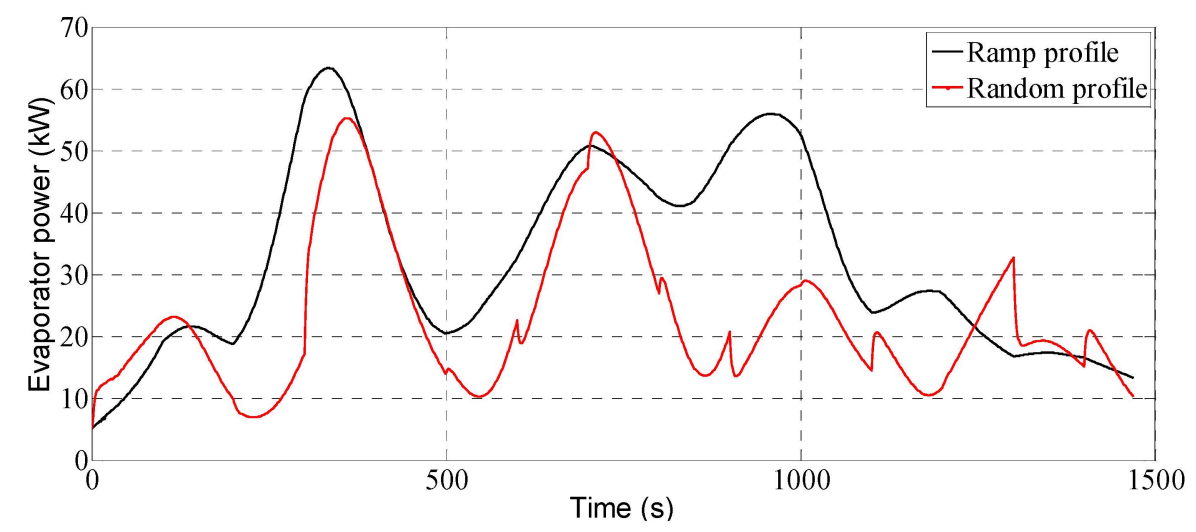

Figure 10. Evaporator power of the FV model.

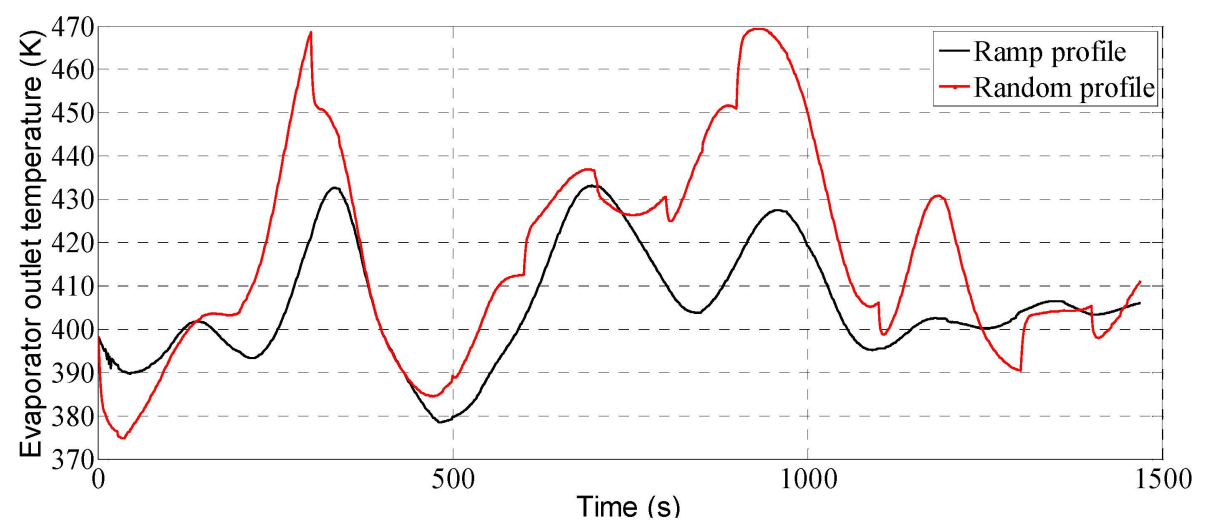

Figure 11. Evaporator outlet temperature of the FV model.

The FV model was run on a personal computer, with the specification shown in Table 3 . Table 4 shows the computation time of the finite volume model for the two different profiles. From the results, it can be observed that the computation time of the finite volume method is very high due to the many iterative loops used in the model. 
Table 3. Computer specifications.

\begin{tabular}{cc}
\hline Operating System & Windows $^{\circledR}$ 7 Enterprise 64-bits \\
\hline Processor & Intel $^{\circledR}$ Core $^{\mathrm{TM}}$ i7-3770 CPU @3.40GHz; 16384MB RAM \\
Programming software & MATLAB $^{\circledR}$ R2014a 64 bits \\
\hline
\end{tabular}

Table 4. Simulation time of the finite volume-based evaporator model.

\begin{tabular}{cc}
\hline Input Profile (each profile contains 1470 data sets) & Simulation Time \\
\hline Ramp profile & $13870(\mathrm{~s})$ \\
Random profile & $14826(\mathrm{~s})$ \\
\hline
\end{tabular}

\section{Fuzzy Evaporator Model}

As described in the above section, although the calculation procedure of the evaporator model using the FV method is clear, the computation time is too high. This poor performance will restrict the model for use in a real time control systems. To overcome this drawback, a new fuzzy-based evaporator model is introduced. Detailed construction and working principle of the proposed fuzzy based evaporator model is described in this section.

The fuzzy based evaporator model is designed with three inputs and two outputs and is shown in Figure 12. The inputs of the model are mass flow rate of refrigerant $\dot{m}_{r}$, mass flow rate of hot fluid $\dot{m}_{h}$ and temperature of hot fluid $T_{h}$; and the outputs are the evaporator power $Q_{e v}$ and outlet temperature $T_{e v}$.

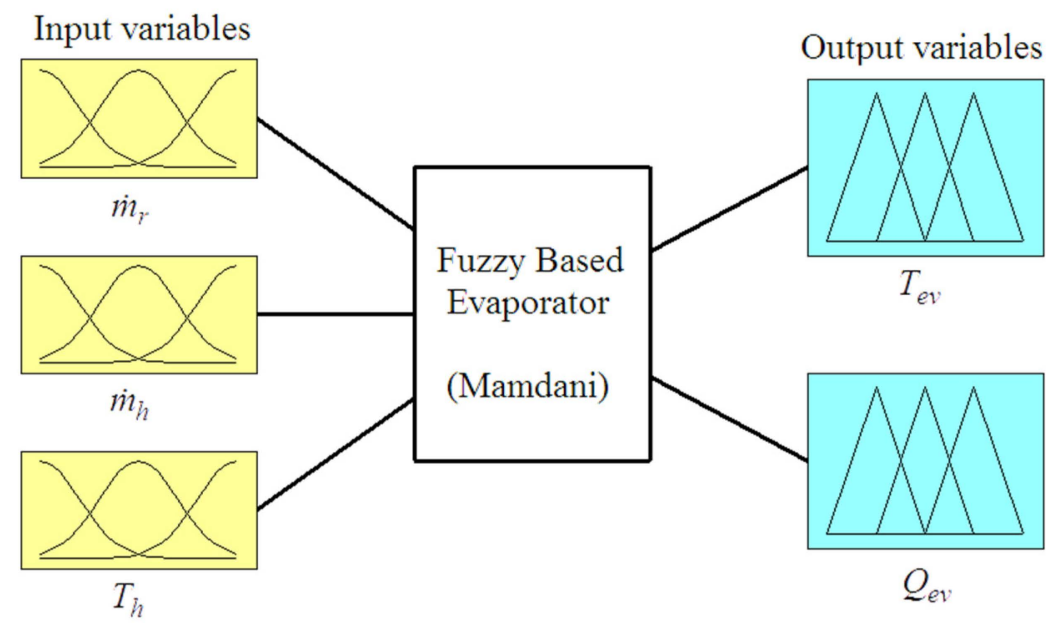

Figure 12. Three inputs and two outputs fuzzy inference system for the evaporator.

Figure 13 shows the structure of the fuzzy based evaporator model with three inputs and two outputs. The fuzzy evaporator model in this paper is built using the fuzzy technique introduced by Mamdani and Assilian [20]. The fuzzy model represents the nonlinear system of the evaporator by mapping its input variables to the output variables. A fuzzy model typically consists of fuzzy logic, membership functions, fuzzy sets, and fuzzy rules [22]. The fuzzy logic is a multivalued logical system that provides the value of an unknown output by attaching the degree of known input and output of the system [32]. The inputs and outputs ranges of the evaporator model are divided into linguistic levels; each of these levels is called a membership function. The collection of membership functions is termed as a fuzzy set. The fuzzy rules of the evaporator are created using fuzzy IF-THEN statements. The fuzzy based evaporator model consists of a fuzzification unit, a knowledge based unit, an implication unit and a defuzzification unit as shown in Figure 13. 


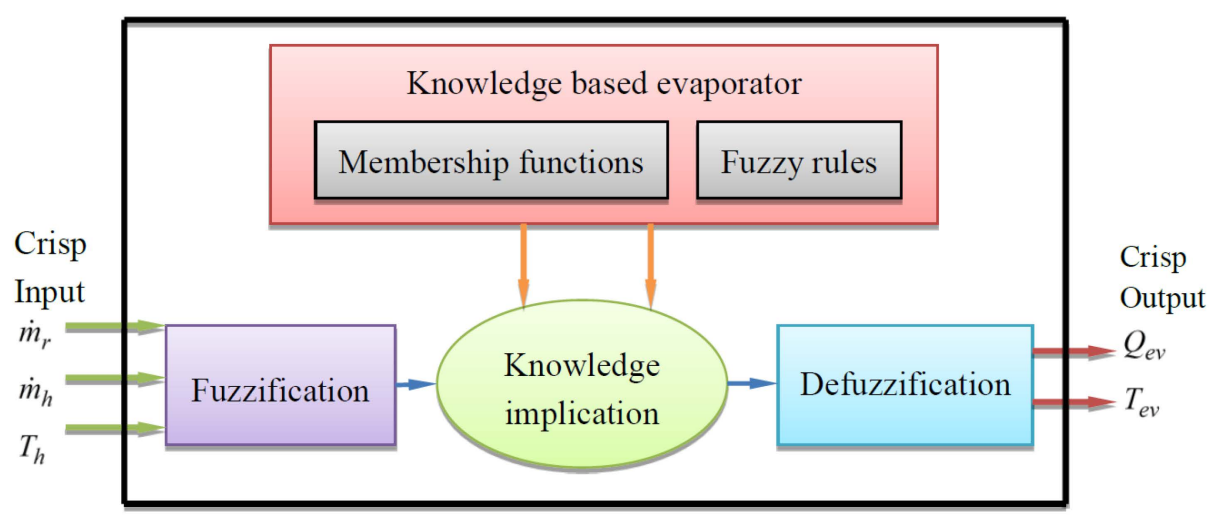

Figure 13. Fuzzy based evaporator model.

Steps to implement the proposed fuzzy based evaporator model are as follows:

Step 1: Range identification

The variable ranges of the fuzzy based evaporator are determined from the input and output profiles and adjusted from the experience of the system as follows: $\left[\dot{m}_{r \min }, \dot{m}_{r \max }\right]=[28.6(\mathrm{gm} / \mathrm{s})$, $255(\mathrm{gm} / \mathrm{s})],\left[\dot{m}_{h \min }, \dot{m}_{h \max }\right]=[50(\mathrm{gm} / \mathrm{s}), 300(\mathrm{gm} / \mathrm{s})],\left[T_{h \min }, T_{h \max }\right]=[403(\mathrm{~K}), 525(\mathrm{~K})]$, $\left[Q_{e v \min }, Q_{e v \max }\right]=[-11(\mathrm{~kW}), 80(\mathrm{~kW})]$ and $\left[T_{e v \min }, T_{e v \max }\right]=[336(\mathrm{~K}), 517(\mathrm{~K})]$, respectively. Each of these input and output value is called a crisp value. The ranges of these variables are shown in Figures 14-18.

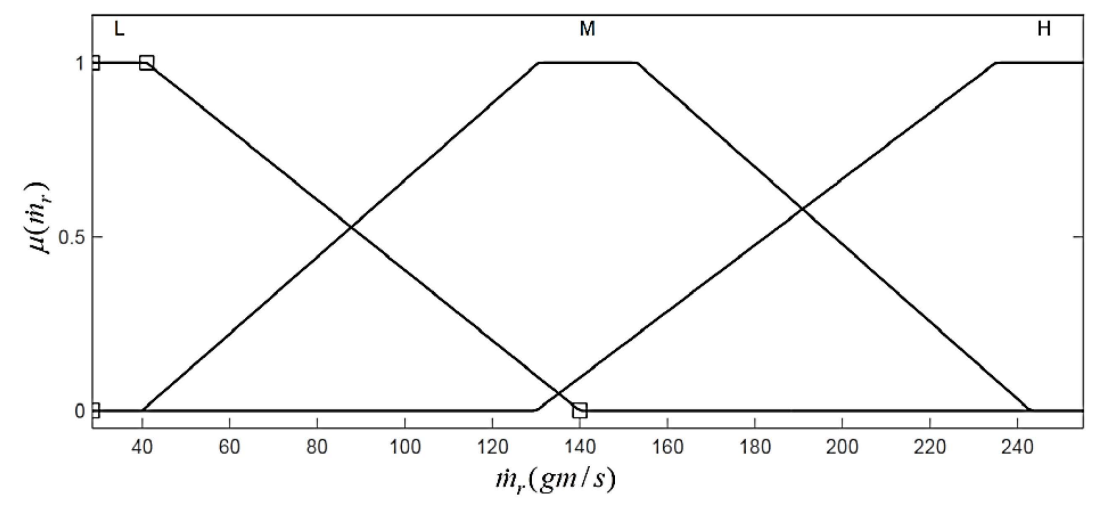

Figure 14. Membership functions of refrigerant mass flow rate.

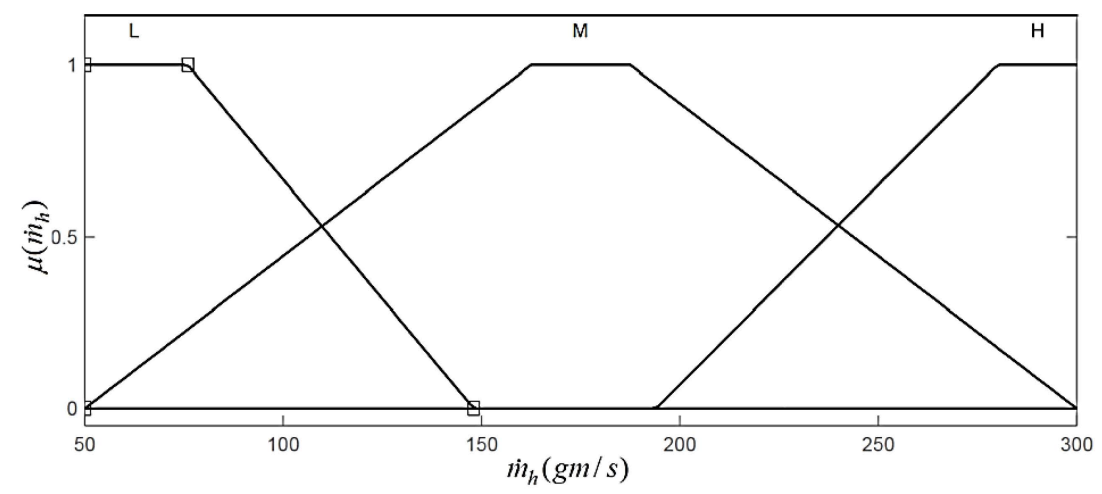

Figure 15. Membership functions of hot fluid mass flow rate. 


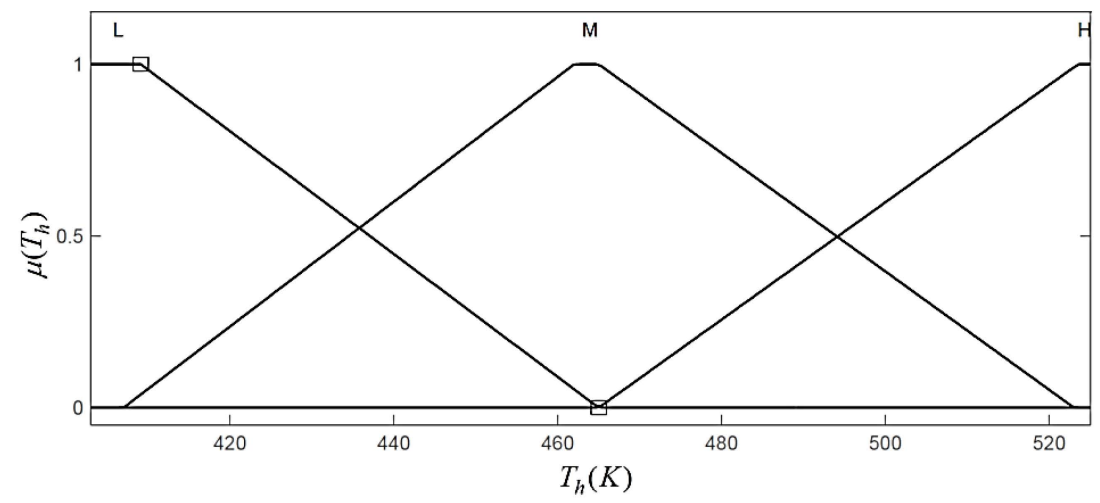

Figure 16. Membership functions of hot fluid temperature.

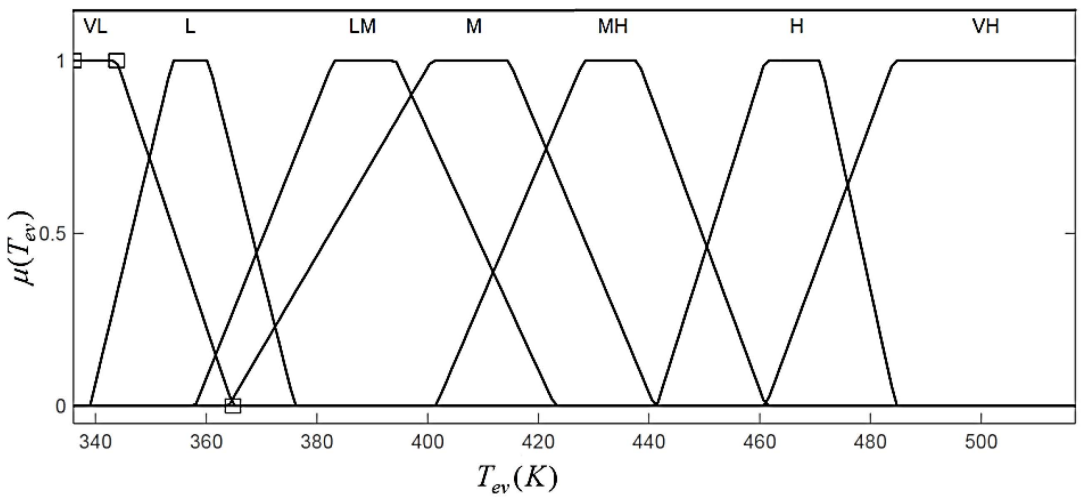

Figure 17. Membership functions of evaporator outlet temperature.

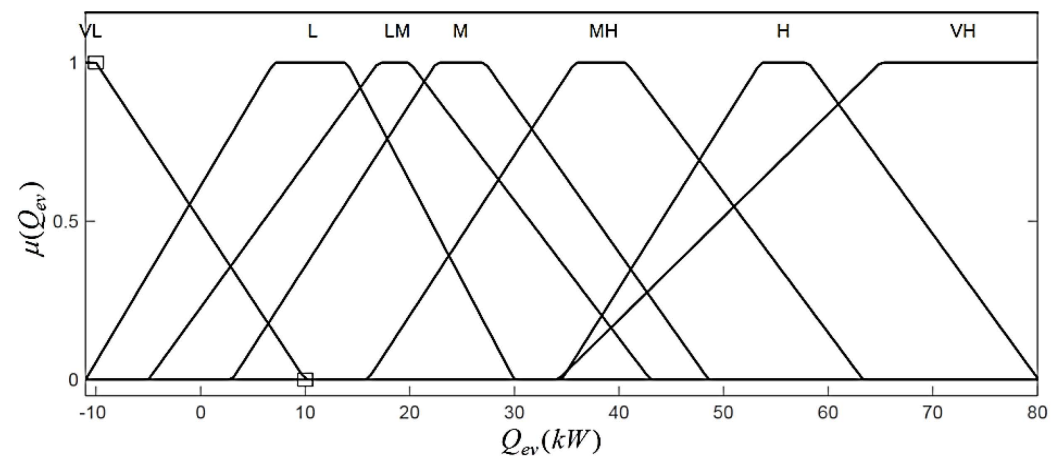

Figure 18. Membership functions of evaporator power.

\section{Step 2: Fuzzification}

In this work, the linguistic levels assigned to the input and output variables are as follows: VL: Very Low; L: Low; LM: Low to Medium; M: Medium; MH: Medium to High; H: High and VH: Very High. The linguistic level in fuzzy inference system is termed as membership function. Each input and output of the proposed fuzzy model consists of three and seven membership functions, respectively. The membership functions of each input and output are determined and adjusted by the experience about the system of the designer. In order to obtain a feasible rule bases with high efficiency, all the input and output values were normalized over the interval [0,1], as shown in Figures 14-18.

L, M and $\mathrm{H}$ are assigned as the fuzzy sets of $\dot{m}_{r}, \dot{m}_{h}$ and $T_{h}$ which are the inputs of the fuzzy model, and the membership functions of the fuzzy sets are shown in Figures 14-16. Similarly, the 
fuzzy sets assigned to the output variables of the model are VL, L, LM, M, MH, H and VH and are shown in Figures 17 and 18.

Step 3: Fuzzy rules and fuzzy inference

Using the above fuzzy sets of the input and output variables, the fuzzy rules applied in the evaporator model are composed as follows:

$$
\text { Rule } i \text { : IF } \dot{m}_{r} \text { is } \alpha_{i} \text { AND } \dot{m}_{h} \text { is } \beta_{i} \text { AND } T_{h} \text { is } \gamma_{i} \text { THEN } T_{e v} \text { is } \delta_{i} \text { AND } Q_{e v} \text { is } \psi_{i}
$$

where $i=1,2,3 \ldots . n, n$ is the number of fuzzy rules, $\alpha_{i}, \beta_{i}, \gamma_{i}, \delta_{i}, \psi_{i}$ are the $i^{\text {th }}$ fuzzy sets of the input and output variables of the fuzzy system. In this research, trapezoidal functions are used as the membership functions, denoted by $\mu$ in Figures 14-18. The numbers of rules for the fuzzy model are dependent on the number of input membership functions used to define the system. The rules are determined from intuition and knowledge of characteristics of the evaporator and are shown in Table 5 and in surfaces in Figures 19-22.

Table 5. Fuzzy rules for the three inputs and two outputs evaporator model.

\begin{tabular}{cccccc}
\hline Rule Number & IF $\dot{m}_{r}$ is & AND $\dot{m}_{h}$ is & AND $T_{h}$ is & THEN $T_{e v}$ is & AND $Q_{e v}$ is \\
\hline 1 & $\mathrm{~L}$ & $\mathrm{~L}$ & $\mathrm{~L}$ & $\mathrm{LM}$ & $\mathrm{VL}$ \\
2 & $\mathrm{~L}$ & $\mathrm{~L}$ & $\mathrm{M}$ & $\mathrm{M}$ & $\mathrm{L}$ \\
3 & $\mathrm{~L}$ & $\mathrm{~L}$ & $\mathrm{H}$ & $\mathrm{VH}$ & $\mathrm{L}$ \\
4 & $\mathrm{M}$ & $\mathrm{L}$ & $\mathrm{L}$ & $\mathrm{VL}$ & $\mathrm{L}$ \\
5 & $\mathrm{M}$ & $\mathrm{L}$ & $\mathrm{M}$ & $\mathrm{LM}$ & $\mathrm{LM}$ \\
6 & $\mathrm{M}$ & $\mathrm{L}$ & $\mathrm{H}$ & $\mathrm{M}$ & $\mathrm{M}$ \\
7 & $\mathrm{H}$ & $\mathrm{L}$ & $\mathrm{L}$ & $\mathrm{VL}$ & $\mathrm{LM}$ \\
8 & $\mathrm{H}$ & $\mathrm{L}$ & $\mathrm{M}$ & $\mathrm{LM}$ & $\mathrm{M}$ \\
9 & $\mathrm{H}$ & $\mathrm{L}$ & $\mathrm{H}$ & $\mathrm{LM}$ & $\mathrm{MH}$ \\
10 & $\mathrm{~L}$ & $\mathrm{M}$ & $\mathrm{L}$ & $\mathrm{LM}$ & $\mathrm{VL}$ \\
11 & $\mathrm{~L}$ & $\mathrm{M}$ & $\mathrm{M}$ & $\mathrm{MH}$ & $\mathrm{L}$ \\
12 & $\mathrm{~L}$ & $\mathrm{M}$ & $\mathrm{H}$ & $\mathrm{VH}$ & $\mathrm{L}$ \\
13 & $\mathrm{M}$ & $\mathrm{M}$ & $\mathrm{L}$ & $\mathrm{L}$ & $\mathrm{LM}$ \\
14 & $\mathrm{M}$ & $\mathrm{M}$ & $\mathrm{M}$ & $\mathrm{M}$ & $\mathrm{M}$ \\
15 & $\mathrm{M}$ & $\mathrm{M}$ & $\mathrm{H}$ & $\mathrm{MH}$ & $\mathrm{MH}$ \\
16 & $\mathrm{H}$ & $\mathrm{M}$ & $\mathrm{L}$ & $\mathrm{L}$ & $\mathrm{M}$ \\
17 & $\mathrm{H}$ & $\mathrm{M}$ & $\mathrm{M}$ & $\mathrm{LM}$ & $\mathrm{MH}$ \\
18 & $\mathrm{H}$ & $\mathrm{M}$ & $\mathrm{H}$ & $\mathrm{MH}$ & $\mathrm{VH}$ \\
19 & $\mathrm{~L}$ & $\mathrm{H}$ & $\mathrm{L}$ & $\mathrm{LM}$ & $\mathrm{VL}$ \\
20 & $\mathrm{~L}$ & $\mathrm{H}$ & $\mathrm{M}$ & $\mathrm{MH}$ & $\mathrm{L}$ \\
21 & $\mathrm{~L}$ & $\mathrm{H}$ & $\mathrm{H}$ & $\mathrm{VH}$ & $\mathrm{L}$ \\
22 & $\mathrm{M}$ & $\mathrm{H}$ & $\mathrm{L}$ & $\mathrm{LM}$ & $\mathrm{LM}$ \\
23 & $\mathrm{M}$ & $\mathrm{H}$ & $\mathrm{M}$ & $\mathrm{M}$ & $\mathrm{M}$ \\
24 & $\mathrm{M}$ & $\mathrm{H}$ & $\mathrm{H}$ & $\mathrm{H}$ & MH \\
25 & $\mathrm{H}$ & $\mathrm{H}$ & $\mathrm{L}$ & $\mathrm{L}$ & M \\
26 & $\mathrm{H}$ & $\mathrm{H}$ & $\mathrm{M}$ & $\mathrm{LM}$ & $\mathrm{H}$ \\
27 & $\mathrm{H}$ & $\mathrm{H}$ & $\mathrm{H}$ & MH & VH \\
\hline
\end{tabular}




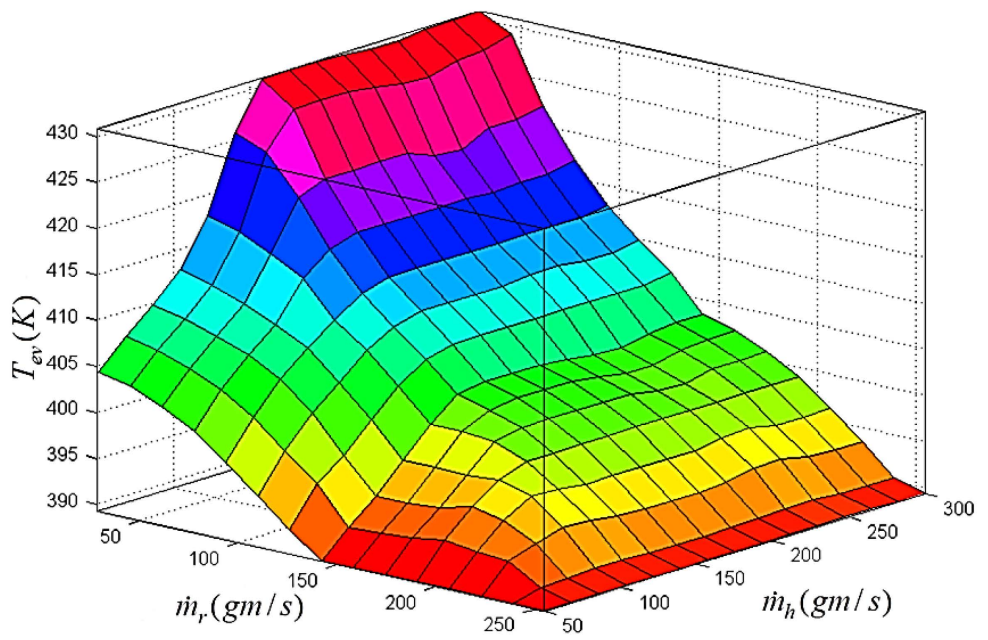

Figure 19. Fuzzy surface for the evaporator outlet temperature with respect to $\dot{m}_{r}$ and $\dot{m}_{h}$.

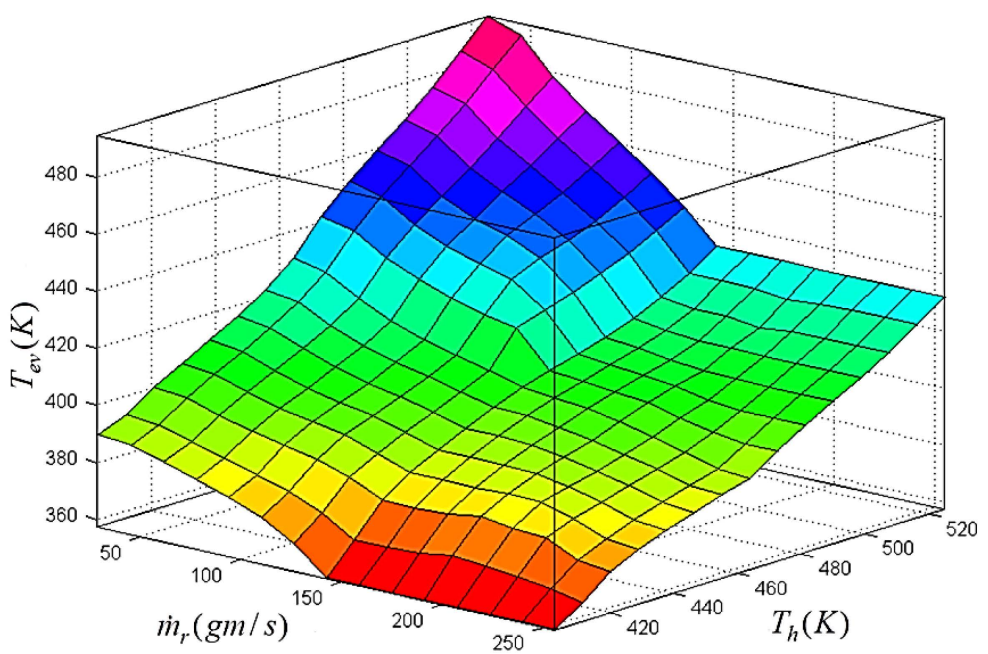

Figure 20. Fuzzy surface for the evaporator outlet temperature with respect to $\dot{m}_{r}$ and $T_{h}$.

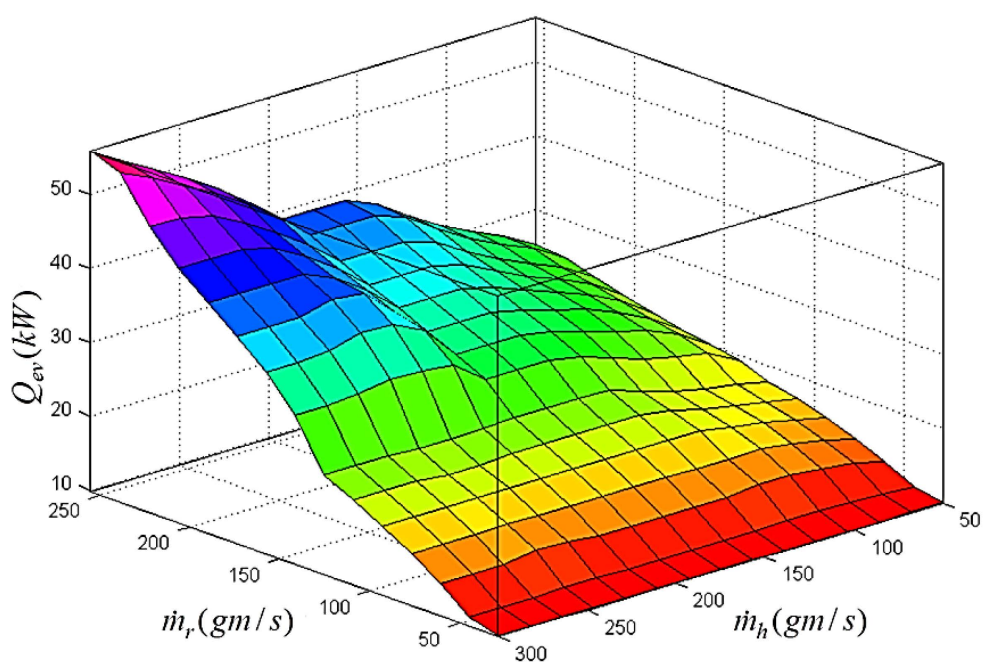

Figure 21. Fuzzy surface for the evaporator power with respect to $\dot{m}_{r}$ and $\dot{m}_{h}$. 


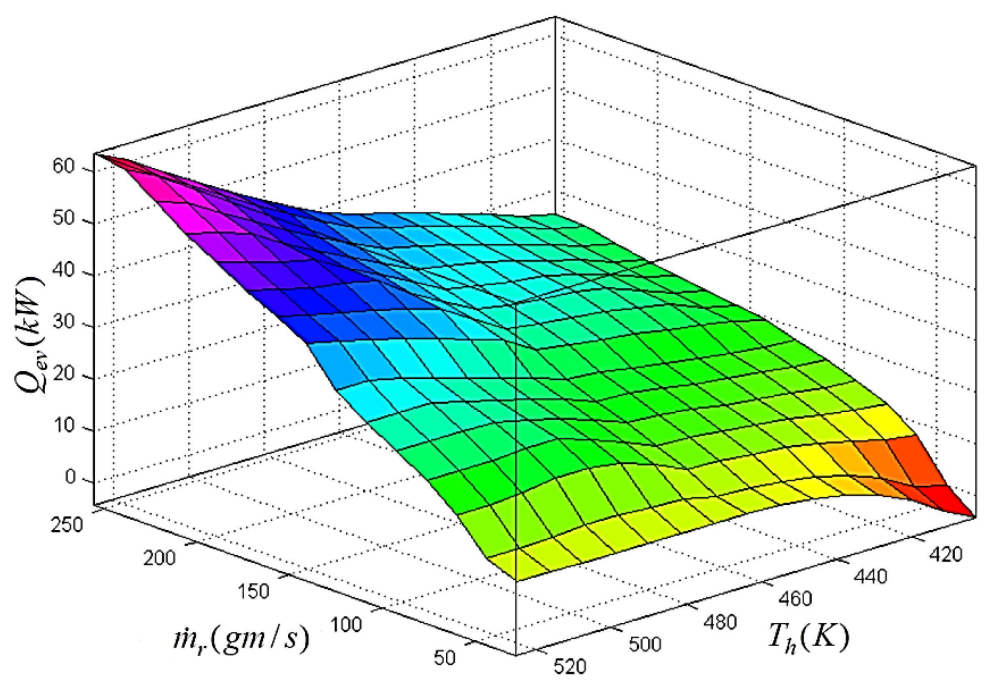

Figure 22. Fuzzy surface for the evaporator power with respect to $\dot{m}_{r}$ and $T_{h}$.

In this work, the MAX-MIN fuzzy reasoning method is used to obtain the output from the inference rule and present input. For given a specific input fuzzy set $\Omega^{\prime}$ in $U$, the output fuzzy set $\Phi^{\prime}$ in $S$ for $T_{e v}$ is computed through the inference system as follows:

$$
\mu_{\Phi}^{\prime}\left(T_{e v}\right)=\max _{l=1}^{n}\left[\operatorname{supmin}_{x \in U}\left(\mu_{\Omega^{\prime}}(x), \mu_{\Omega_{1}^{l}}\left(\dot{m}_{r}\right), \mu_{\Omega_{2}^{l}}\left(\dot{m}_{h}\right), \mu_{\Omega_{3}^{l}}\left(T_{h}\right), \mu_{\Phi^{l}}\left(T_{e v}\right)\right)\right]
$$

The output membership functions for $Q_{e v}$ is calculated similarly.

\section{Step 4: Defuzzification}

The centroid defuzzification method [33] is used in this paper to convert the aggregated fuzzy set to a crisp output value $Y$ from the fuzzy set $\Phi^{\prime}$ in $V \subset R$. This work computes the weighted average of the membership function or the centre of gravity (COG) of the area bounded by the membership function curves:

$$
Y=\frac{\int_{V} \mu_{\Phi^{\prime}}(y) \times y d y}{\int_{V} \mu_{\Phi^{\prime}}(y) d y}
$$

The crisp value of $T_{e v}$ and $Q_{e v}$ were calculated using the above expression.

\section{Simulation Results of Fuzzy Based Evaporator Model}

The performance of the fuzzy model was investigated with the same heat source and input profiles as the finite volume method. The outputs of the fuzzy evaporator model compared with those of the finite volume method with respect to the ramp input profile are presented in Figures 23 and 24. As shown in Figure 23, the fuzzy based model can be used to predict the evaporator power although there are still some small deviations compared with the FV method. The following indicators are used to evaluate the performance of the proposed fuzzy based model compared with the finite volume method:

$$
R M S E=\sqrt{\frac{1}{n} \sum_{j=1}^{n}\left(\sigma_{j}-\bar{\sigma}_{j}\right)^{2}}
$$

where $\sigma_{j}$ is the estimated time series, $\bar{\sigma}_{j}$ is the actual time series and $n$ is the total number of data sets. 


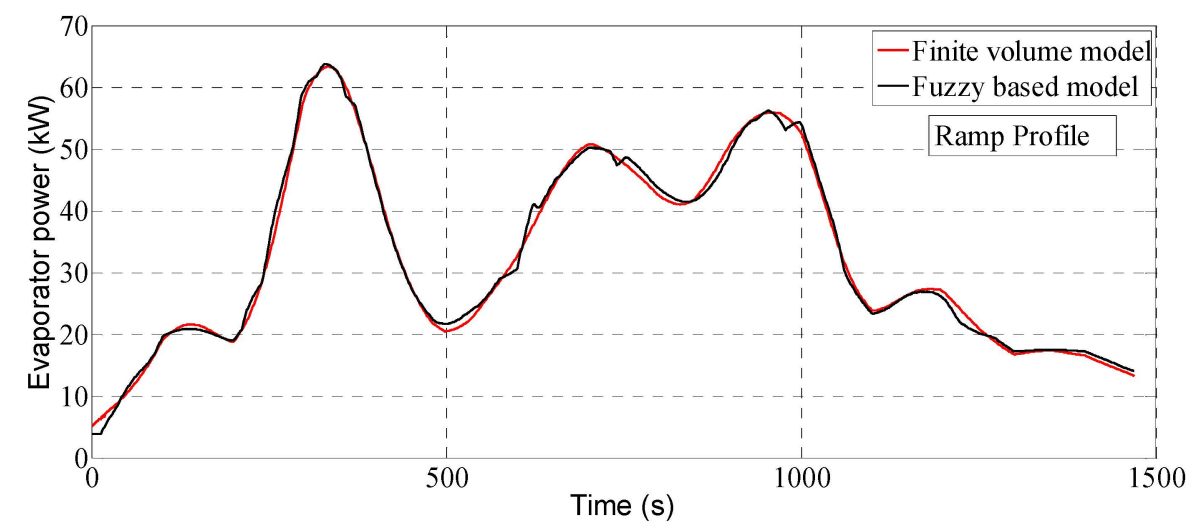

Figure 23. Prediction of the evaporator power with respect to ramp profile.

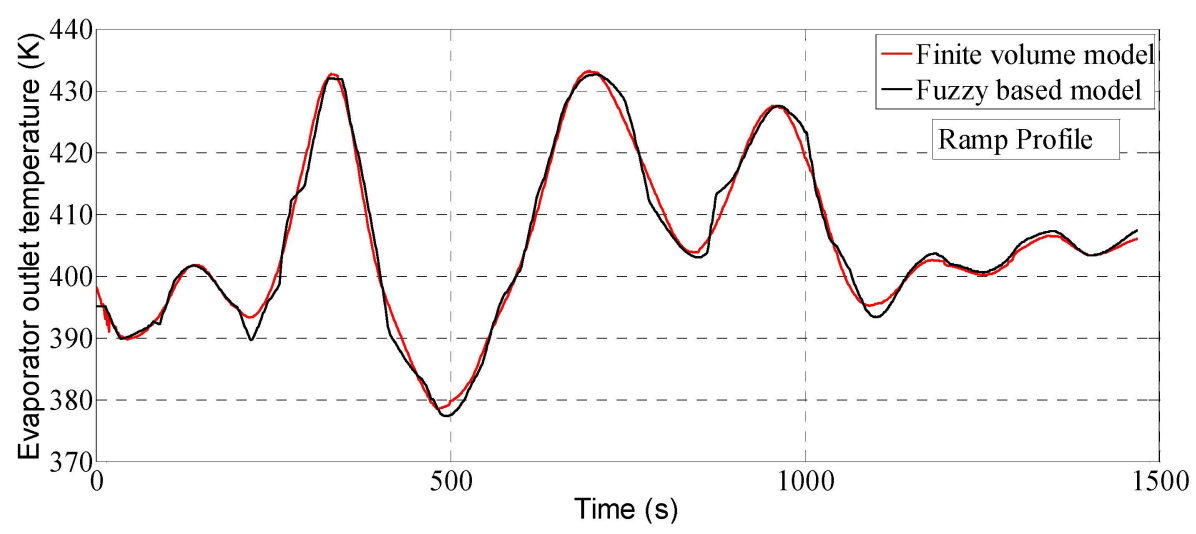

Figure 24. Prediction of the evaporator outlet temperature with respect to ramp profile.

The congruency of the fit between the model outputs of these two methods was also evaluated as follows:

$$
f i t=1-\frac{\left\|\bar{\sigma}_{j}-\sigma_{j}\right\|}{\left\|\bar{\sigma}_{j}-\operatorname{mean}\left(\bar{\sigma}_{j}\right)\right\|}
$$

Table 6 shows the RMSE and fitness values of the fuzzy based evaporator model compared with the finite volume method with respect to difference input profiles. The RMSE value of the evaporator power $Q_{e v}$ for the ramp profile is $0.95 \mathrm{~kW}$; while the congruency of the fit of the fuzzy model is $93.68 \%$. Similarly, the evaporator outlet temperature of the fuzzy based model was compared to that of a finite volume model which is shown in Figure 24. The RMSE and congruency of the fit of the fuzzy model output for ramp profile are $1.48 \mathrm{~K}$, and $89.16 \%$, respectively.

Table 6. Performance of the fuzzy based evaporator model.

\begin{tabular}{cccc}
\hline Performance Indicator & RMSE & Fitness (\%) & Simulation Time \\
\hline$Q_{e v}$-Ramp Profile & $0.95(\mathrm{~kW})$ & 93.68 & \multirow{2}{*}{ Almost instantly $(<1 \mathrm{~s})$} \\
$T_{e v}$-Ramp Profile & $1.48(\mathrm{~K})$ & 89.16 & \\
\hline$Q_{e v}$-Random Profile & $0.92(\mathrm{~kW})$ & 92.31 & \multirow{2}{*}{ Almost instantly $(<1 \mathrm{~s})$} \\
$T_{e v}$-Random Profile & $3.02(\mathrm{~K})$ & 87.00 & \\
\hline
\end{tabular}

Figures 25 and 26 show the evaporator outputs of the fuzzy and FV model with respect to the random mass flow rate profile. The RMSE and data fitness values are $0.92 \mathrm{~kW}$ and $92.31 \%$ for the evaporator power, $3.02 \mathrm{~K}$ and $87 \%$ for the evaporator outlet temperature, respectively. It can be seen from the Figures 25 and 26 that the fuzzy model can accurately forecast the evaporator 
outputs within all the operation ranges. However, since the membership functions and fuzzy rules were not optimized during the design of the fuzzy based evaporator model, there are small errors at some areas as shown in Figures 23-26. These discrepancies can be improved by adjusting and optimizing the membership functions and their linguistic levels based on the knowledge about the evaporator operation.

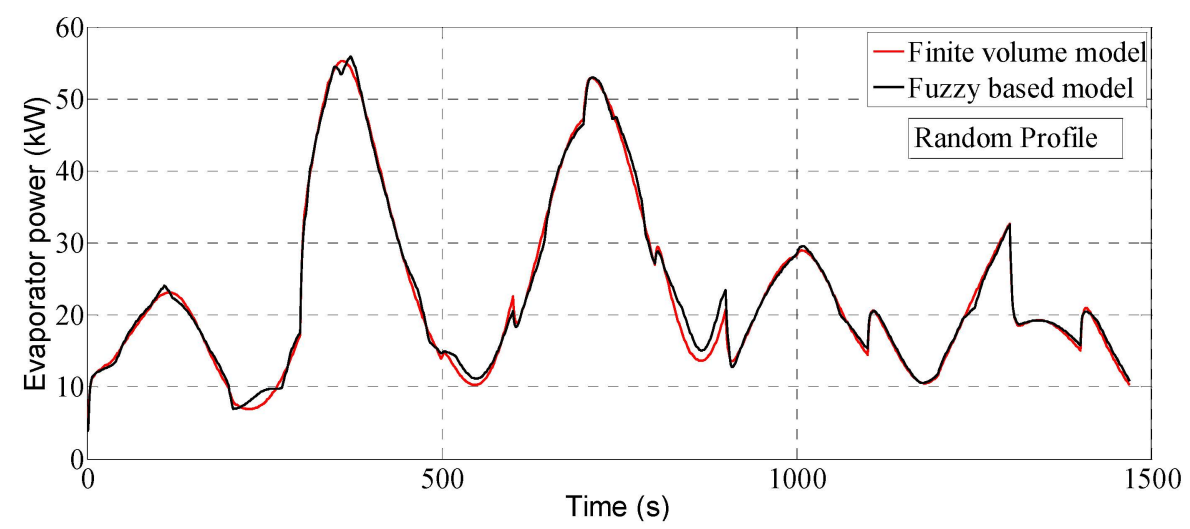

Figure 25. Prediction of evaporator power with respect to random profile.

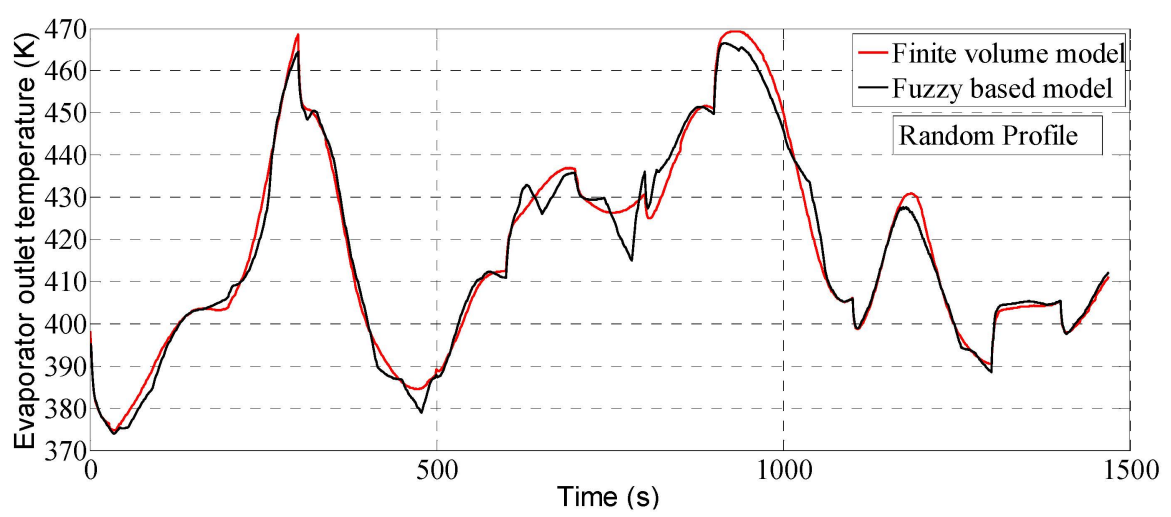

Figure 26. Prediction of evaporator outlet temperature with respect to random profile.

The fuzzy based model outputs for both profiles are obtained in less than 1 second. On the other hand, the computation times of the FV model for the ramp and random profiles are 13,870 and 14,826 s, respectively. Comparing with the FV method, the proposed fuzzy based model saves a large amount of computation time as it can calculate the model outputs almost instantly.

\section{Conclusions}

In this paper a new fuzzy based evaporator model was developed and compared with the conventional finite volume method. Although the finite volume technique can be used to calculate the outputs of the evaporator, the use of this model in the simulation and real time control of a waste heat recovery system is not viable due to the highly time consuming algorithms. The fuzzy-based model proposed in this paper does not require complex iteration loops and therefore it can reduce the computation time significantly and the model output can be calculated almost instantly. Since the fuzzy rules can be modified with knowledge and experience about the system, the proposed fuzzy based evaporator model can be used in the development of a real time control system for the waste heat recovery process. Although the fuzzy model presented in this paper is able to reduce the computation time for the evaporator outputs, the membership functions and fuzzy rules need to be adjusted if there is any change in the system, for example, a new size or layout of the heat exchanger. 
As the WHR process is also often associated with transient heat sources in the hot side and slow changes in the cold side of the evaporator; it is necessary to incorporate the thermal inertia in the evaporator model. This will be the focus of future research in this area.

Acknowledgments: This work is a part of the Ph.D. project supported by the Queen's Special Research Scholarship, School of Mechanical and Aerospace Engineering (Queen's University Belfast, UK). This sponsorship is gratefully acknowledged.

Author Contributions: Jahedul Islam Chowdhury planned the methods, developed the programming code, carried out the simulation cases and wrote the manuscript as the first author. Bao Kha Nguyen provided the ideas for the cases, supported in developing the code, contributed in writing and reviewed the manuscript. David Thornhill revised the final manuscript and provided valuable suggestions. All authors agreed about the contents and approved the manuscript for submission.

Conflicts of Interest: The authors declare no conflict of interest.

\section{Nomenclature}

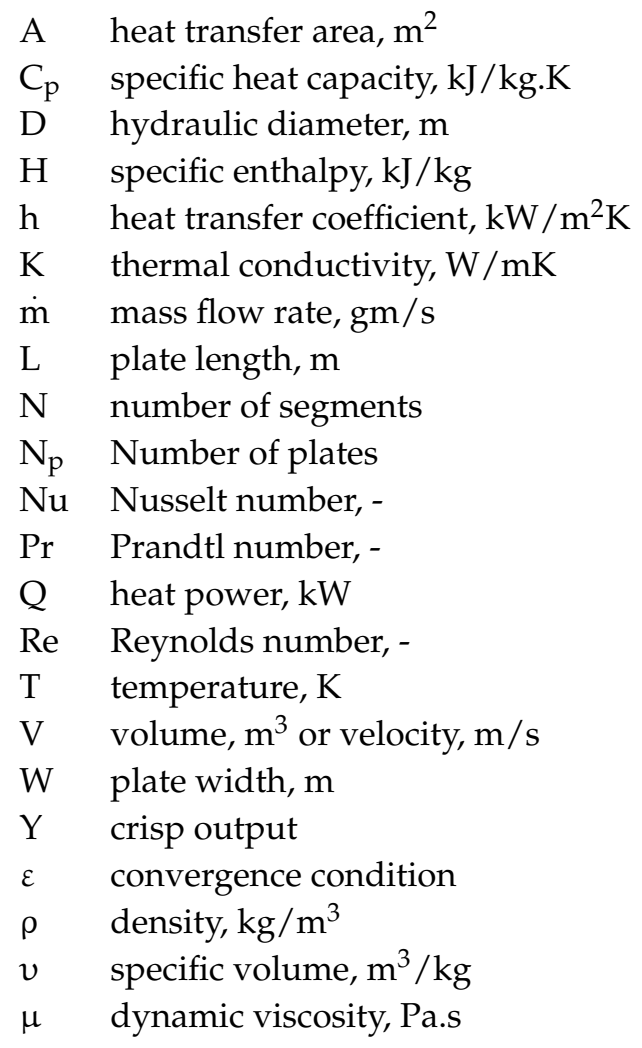

\section{Subscripts}

b bulk

$r$ refrigerant

h hot fluid

i in or inlet

o out or outlet

ev evaporator

pc pseudo-critical

j segment or cell

wall evaporator wall 


\section{References}

1. Glover, S.; Douglas, R.; Glover, L.; McCullough, G. Preliminary analysis of Organic Rankine Cycles to improve vehicle efficiency. Proc. IMechE D J. Automob. Eng. 2014, 228, 1142-1153. [CrossRef]

2. Quoilin, S.; Aumann, R.; Grill, A.; Schuster, A.; Lemort, V.; Spliethoff, H. Dynamic modeling and optimal control strategy of waste heat recovery Organic Rankine Cycles. Appl. Energy 2011, 88, 2183-2190. [CrossRef]

3. Quoilin, S.; Declaye, S.; Tchanche, B.F.; Lemort, V. Thermo-economic optimization of waste heat recovery Organic Rankine Cycles. Appl. Therm. Eng. 2011, 31, 2885-2893. [CrossRef]

4. Schuster, A.; Karellas, S.; Aumann, R. Efficiency optimization potential in supercritical Organic Rankine Cycles. Energy 2010, 35, 1033-1039. [CrossRef]

5. Shu, G.; Yu, G.; Tian, H.; Wei, H.; Liang, X. A multi-approach evaluation system (MA-ES) of Organic Rankine Cycles (ORC) used in waste heat utilization. Appl. Energy 2014, 132, 325-338. [CrossRef]

6. Gao, H.; Liu, C.; He, C.; Xu, X.; Wu, S.; Li, Y. Performance analysis and working fluid selection of a supercritical Organic Rankine Cycle for low grade waste heat recovery. Energies 2012, 5, 3233-3247. [CrossRef]

7. Lecompte, S.; Huisseune, H.; van den Broek, M.; de Paepe, M. Methodical thermodynamic analysis and regression models of Organic Rankine Cycle architectures for waste heat recovery. Energy 2015, 87, 60-76. [CrossRef]

8. Chen, H.J.; Goswami, D.Y.; Rahman, M.M.; Stefanakos, E.K. A supercritical Rankine cycle using zeotropic mixture working fluids for the conversion of low-grade heat into power. Energy 2011, 36, 549-555. [CrossRef]

9. Tian, H.; Shu, G.; Wei, H.; Liang, X.; Liu, L. Fluids and parameters optimization for the Organic Rankine Cycles (ORCs) used in exhaust heat recovery of Internal Combustion Engine (ICE). Energy 2012, 47, 125-136. [CrossRef]

10. Wang, Z.Q.; Zhou, N.J.; Guo, J.; Wang, X.Y. Fluid selection and parametric optimization of Organic Rankine Cycle using low temperature waste heat. Energy 2012, 40, 107-115. [CrossRef]

11. Sun, J.; Li, W. Operation optimization of an Organic Rankine Cycle (ORC) heat recovery power plant. Appl. Therm. Eng. 2011, 31, 2032-2041. [CrossRef]

12. Zhang, J.; Zhou, Y.; Li, Y.; Hou, G.; Fang, F. Generalized predictive control applied in waste heat recovery power plants. Appl. Energy 2013, 102, 320-326. [CrossRef]

13. Hou, G.; Sun, R.; Hu, G.; Zhang, J. Supervisory predictive control of evaporator in Organic Rankine Cycle (ORC) system for waste heat recovery. In Proceedings of the International Conference on Advanced Mechatronic Systems, Zhengzhou, China, 11-13 August 2011.

14. Zhang, J.; Zhang, W.; Hou, G.; Fang, F. Dynamic modeling and multivariable control of Organic Rankine Cycles in waste heat utilizing processes. Comput. Math. Appl. 2012, 64, 908-921. [CrossRef]

15. Quoilin, S.; Lemort, V.; Lebrun, J. Experimental study and modeling of an Organic Rankine Cycle using scroll expander. Appl. Energy 2010, 87, 1260-1268. [CrossRef]

16. Zhang, J.; Zhou, Y.; Wang, R.; Xu, J.; Fang, F. Modeling and constrained multivariable predictive control for ORC (Organic Rankine Cycle) based waste heat energy conversion systems. Energy 2014, 66, 128-138. [CrossRef]

17. Feru, E.; Willems, F.; Jager, B.D.; Steinbuch, M. Modeling and control of a parallel waste heat recovery system for Euro-VI heavy-duty diesel engines. Energies 2014, 7, 6571-6592. [CrossRef]

18. Karellasa, S.; Schuster, A.; Leontaritis, A.-D. Influence of supercritical ORC parameters on plate heat exchanger design. Appl. Therm. Eng. 2012, 33, 70-76. [CrossRef]

19. Patiño, J.; Llopis, R.; Sánchez, D.; Sanz-Kock, C.; Cabello, R.; Torrella, E. A comparative analysis of a $\mathrm{CO}_{2}$ evaporator model using experimental heat transfer correlations and a flow pattern map. Int. J. Heat Mass Transfer 2014, 71, 361-375. [CrossRef]

20. Mamdani, E.; Assilian, S. An experiment in linguistic synthesis with a fuzzy logic controller. Int. J. Man-Mach. Stud. 1975, 7, 1-13. [CrossRef]

21. Nguyen, B.K.; Ahn, K.K. Feedforward control of shape memory alloy actuators using fuzzy-based inverse preisach model. IEEE Trans. Control Syst. Techol. 2009, 17, 434-441. [CrossRef] 
22. Mehran, K. Takagi-Sugeno fuzzy modeling for process control. In Industrial Automation, Robotics and Artificial Intelligence (EEE8005); Newcastle University: Newcastle upon Tyne, UK, 2008.

23. Keshwani, D.R.; Jones, D.D.; Meyer, G.E.; Brand, R.M. Rule-based Mamdani-type fuzzy modeling of skin permeability. Appl. Soft Comput. 2008, 8, 285-294. [CrossRef]

24. Thulukkanam, K. Heat Exchnager Design Handbook, 2nd ed.; Chemical Rubber Company (CRC) Press: Boca Raton, FL, USA, 2013.

25. Zhang, H.; Wang, E.; Fan, B. Heat transfer analysis of a finned-tube evaporator for engine exhaust heat recovery. Energy Convers. Manag. 2013, 65, 438-447. [CrossRef]

26. Bamgbopa, M.O.; Uzgoren, E. Numerical analysis of an Organic Rankine Cycle under steady and variable heat input. Appl. Energy 2013, 107, 219-228. [CrossRef]

27. GEA Heat Exchangers, Inc. PHE Division. GEA Heat Exchangers, January 2014. Available online: http:/ / www.gea-phe.com/usa (accessed on 15 August 2014).

28. Jackson, J.D.; Hall, W.B. Forced convection heat transfer to fluids at supercritical pressure. In Turbulent Forced Convection in Channels and Bundles; Kakac, S., Spalding, D.B., Eds.; Hemisphere: New York, NY, USA, 1979; Volume 2, pp. 563-611.

29. Jackson, J.D.; Hall, W.B. Influences of buoyancy on heat transfer to fluids flowing in vertical tubes under turbulent conditions. In Turbulent Forced Convection in Channels and Bundles; Kakac, S., Spalding, D.B., Eds.; Hemisphere: New York, NY, USA, 1979; Volume 2, pp. 613-640.

30. Sharabi, M.; Ambrosini, W.; He, S.; Jackson, J.D. Prediction of turbulent convective heat transfer to a fluid at supercritical pressure in square and triangular channels. Ann. Nucl. Energy 2008, 35, 993-1005. [CrossRef]

31. Lemmon, E.W.; Huber, M.L.; McLinden, M.O. NIST Standard Reference Database 23: Reference Fluid Thermodynamic and Transport Properties-REFPROP, Version 9.0; National Institute of Standards and Technology: Gaithersburg, MD, USA, 2010.

32. Control system principle.co.uk; Vernon, J. Fuzzy logic systems. Available online: http://www.controlsystems-principles.co.uk (accessed on 15 April 2015).

33. Ross, T.J. Fuzzy Logic with Engineering Applications; McGraw-Hill Inc.: New York, NY, USA, 1995.

(C) 2015 by the authors; licensee MDPI, Basel, Switzerland. This article is an open access article distributed under the terms and conditions of the Creative Commons by Attribution (CC-BY) license (http:/ / creativecommons.org/licenses/by/4.0/). 